\title{
An Imperfect Production Inventory Model with Remanufacturing of Return and Defective Items
}

\author{
Prasanta Kumar Ghosh \\ Department of Mathematics \\ Y. S. Palpara Mahavidyalaya \\ Palpara, Purba Medinipur, \\ West Bengal, India
}

\author{
Jayanta Kumar Dey \\ Department of Mathematics \\ Mahisadal Raj College \\ Mahisadal , Purba Medinipur \\ West Bengal, India
}

\begin{abstract}
This paper focuses on an inventory model considering imperfect manufacturing and re-manufacturing system under single management. In manufacturing system, the items are produced from original raw materials but in re-manufacturing process, returned and defective items produced in previous manufacturing process are the raw materials. Both the production system shift from ' in control state ' to 'out-control state' at any random time and starts to produce imperfect items. Here the screening process of produced items in both production system (manufacturing and remanufacturing) has been considered during production period. Some portion of the defective items produced from manufacturing process are transformed as good as new after some rework and remaining portion are used as a raw materials in re-manufacturing process. Returned items are collected from the market continuously and stock them for use as raw-materials in remanufacturing system. Inventory costs of produced items, return and defective items are calculated and total cost per unit time is minimized for optimal return lot. Finally some numerical example has been illustrated to study the practical feasibility of the model.
\end{abstract}

\section{Keywords}

Imperfect Production, Manufacturing system, Returneditems, Remanufacturing system, Rework, Return lot.

\section{INTRODUCTION}

In most of the models, researchers consider that the produced products are perfect in nature. But, in real life situation, it is often see that some of the items may be defective in nature which are reworked at a cost to make them perfect. The production of imperfect items are due to long run of the production process, machine breakdown, labor problem, etc. Several researchers have investigated inventory model related with imperfect production system; some of them are Rosenblatt and Lee (1986), Ben-Daya and Hariga (2000), Hayek and Salameh (2001), Goyal and Cardenas-Barron (2002), Chung and Hou(2003), Goyal,Hung and Chen (2003), Sana, Goyal and Chaudhuri(2007), Hazari et.al (2014a, 2014b, 2015), Manna et. al. (2014, 2016), Ghosh (2016) etc.

\section{** Corresponding Author.}

Inventory management in reverse logistic (e.g, recycling, remanufacturing, repairing, etc.) that incorporate joint manufacturing and remanufacturing option has been receiving increasing attention in recent years. Although reverse logistic is relatively new term, the earliest approach in this area was made by Schrady (1967). He developed an inventory model for repairable items that determines the optimal procurement and repair quantities. Nahmias and Rivera (1979) extended Shrady's model to allow for the case of finite recycling/repair rate. Richter (1996a, 1996b, 1997), Richter and Dobos (1999,
2000) have investigated a waste disposal model where optimal number of remanufacturing and production batches depending on the return rate. Some researcher developed models similar to those of Schrady and Richter, but with different assumptions (e.g., Tunter (2001, 2002, 2004), Inderfurth et. al.(2005), Dobos and Richter (2003, 2004, 2006), Konstantaras and Papachristos (2006), Jabar and Rosen (2008), etc.). Jaber and Saadany (2010) have extended the production, remanufacturing and waste disposal model by assuming learning effect to occur in both production and remanufacturing process. Nenes et. al. (2010) have investigated alternative policies for a system where both demand of new products and returns of used products are stochastic. Almari (2010) presented an unified general inventory model for integrated production of new items and remanufacturing of return items for an infinite planning horizon. He considered a production environment that consists of three shops and the items are deteriorating while they are in storage.This paper extend the research of Almari (2010) with imperfect production in which the production system shifts from 'in-control state' to 'out-control state' at random time. Here the screening process of produced items in both production system (manufacturing and remanufacturing) has been considered during production period. Some portion of the defective items produced from manufacturing process are transformed as good as new after some rework and remaining portion are used as a raw materials in re-manufacturing process. Returned items are collected from the market continuously and stock them for use as raw-materials in remanufacturing system. Inventory costs of produced items, return and defective items are calculated and total cost per unit time is minimized for optimal return lot.

\section{MATHEMATICAL FORMULATION OF PROSOSED INVENTORY MODEL}

The following assumptions and notations are adopted for this model.

\subsection{Assumptions}

1. The model is developed for single product.

2. Manufacturing and remanufacturing process are consider under single management.

3. Both the systems are shifted from the 'in-control state' to the 'out-of control state' at any random time point during the manufacturing/remanufacturing run and produces imperfect quality items.

4. Rework of the imperfect product is consider only in the manufacturing cycle at the end of manufacturing up time.

5. Used items are collected from the market and consider as returned items. 
6. Both the returned and non-reworking imperfect (defective) items in the manufacturing system are used as the raw material of the remanufacturing system to protect the environment from the pollution and to save the natural raw material.

7. A certain cost is incurred for environment protection to dispose the defective items in remanufacturing cycle.

8. Total screening is performed for new product and returned items.

9. The time horizon is infinite.

10. Lead time is assumed to be negligible.

11. Deteriorations of the products is not consider.

12. Shortages are not allowed.

\subsection{Notations}

\begin{tabular}{|ll|l|}
\hline $\mathrm{p}_{1}$ & $:$ & Remanufacturing rate of product ( constant). \\
\hline $\mathrm{p}_{2}$ & $:$ & Manufacturing rate of product ( constant). \\
\hline $\mathrm{d}$ & $:$ & Demand rate of perfect quality items. \\
\hline $\mathrm{r}$ & $:$ & Returned rate of used items from the market. \\
\hline $\mathrm{I}_{\mathrm{m}}(\mathrm{t})$ & $:$ & $\begin{array}{l}\text { Inventory of the perfect quality items at time } \mathrm{t} \\
\text { in manufacturing process. }\end{array}$ \\
\hline $\mathrm{I}_{\mathrm{rm}}(\mathrm{t})$ & $:$ & $\begin{array}{l}\text { Inventory of the perfect quality items at time } \mathrm{t} \text { in } \\
\text { remanufacturing process }\end{array}$ \\
\hline $\mathrm{I}_{\mathrm{r}}(\mathrm{t})$ & $:$ & Inventory of the returned items at time $\mathrm{t}$. \\
\hline $\mathrm{Q}$ & $:$ & Total Inventory in the production cycle. \\
\hline $\mathrm{t}_{\mathrm{p}}$ & $:$ & Time of remanufacturing up time. \\
\hline $\mathrm{t}_{1}$ & $:$ & Time of remanufacturing cycle. \\
\hline $\mathrm{t}_{\mathrm{m}}$ & $:$ & Time of manufacturing uptime . \\
\hline $\mathrm{t}_{2}$ & $:$ & Time of manufacturing uptime . \\
\hline $\mathrm{T}$ & $:$ & $\begin{array}{l}\text { Total cycle time for single management } \\
\text { production system of both remanufacturing } \\
\text { and manufacturing process. }\end{array}$ \\
\hline $\mathrm{c}_{\mathrm{m}}$ & $:$ & $\begin{array}{l}\text { Production cost per item per unit time } \\
\text { in manufacturing process. }\end{array}$ \\
\hline $\mathrm{c}_{\mathrm{rm}}$ & $:$ & $\begin{array}{l}\text { Production cost per item per unit time } \\
\text { in remanufacturing process. }\end{array}$ \\
\hline $\mathrm{c}_{\mathrm{s}}$ & $:$ & Screening cost per unit item. \\
\hline $\mathrm{c}_{\mathrm{dm}}$ & $:$ & Disposal cost per unit item/unit time. \\
\hline $\mathrm{c}_{\mathrm{e}}$ & $:$ & Environmental protection cost per unit item. \\
\hline $\mathrm{c}_{\mathrm{r}}$ & $:$ & Return item cost per unit item. \\
\hline $\mathrm{c}_{\mathrm{rr}}$ & $:$ & Rework cost per unit item/time. \\
\hline $\mathrm{h}_{\mathrm{m}}$ & $:$ & $\begin{array}{l}\text { Inventory holding cost per unit item per unit } \\
\text { time in manufacturing process. }\end{array}$ \\
\hline $\mathrm{h}_{\mathrm{rm}}$ & $:$ & $\begin{array}{l}\text { Inventory holding cost per unit item per unit time } \\
\text { in re-manufacturing process. }\end{array}$ \\
\hline $\mathrm{h}_{\mathrm{r}}$ & $:$ & Returned item holding cost per item /time. \\
\hline $\mathrm{k}$ & $:$ & Fixed setup cost. \\
\hline$\delta$ & $:$ & $\begin{array}{l}\text { Rate of imperfect items produced } \\
\text { in remanufacturing processes. }\end{array}$ \\
\hline$\mu$ & $:$ & Rate of imperfect items produced in \\
\hline & & \\
\hline
\end{tabular}

\begin{tabular}{|ll|l|}
\hline & & manufacturing processes. \\
\hline $\mathrm{V}$ & $:$ & $\begin{array}{l}\text { Random variable denoting the shifting of } \\
\text { the process from in-control state to out of } \\
\text { control state in the remanufacturing process . }\end{array}$ \\
\hline $\mathrm{f}(\mathrm{v}) \quad:$ & Density function of V \\
\hline $\mathrm{U}$ & $:$ & $\begin{array}{l}\text { Random variable denoting the shifting of } \\
\text { the process from in-control state to out } \\
\text { of control state the in the manufacturing process . }\end{array}$ \\
\hline $\mathrm{g}(\mathrm{u}) \quad:$ & Density function of U. \\
\hline ATC $\quad:$ & Total cost per unit time. \\
\hline ATC(Q) & Total cost per unit returned lot. \\
\hline
\end{tabular}

\subsection{Mathematical formulation}

Consider a reverse logistic model of which both the remanufacturing and manufacturing process are imperfect, and at a random time point both the process are shift to out of control state from in control state and produces imperfect items. For remanufacturing cycle, $I_{\mathrm{rm}}(\mathrm{t})$ denotes the inventory level at time $t$. The system of remanufacturing starts at $t=0$ with rate $\mathrm{p}_{1}$ and the inventory of perfect items increases at a rate $p_{1}-d-\frac{E\left(n_{1}\right)}{t_{p}}(>0)$ until time $\mathrm{t}=\mathrm{t}_{\mathrm{p}}$, at the same duration the inventory of returned items reaches at zero at a rate $\left(-\mathrm{p}_{1}+\right.$ $r)$, After then the inventory of re-manufacturing perfect items decline continuously at a rate $\mathrm{d}$ and it becomes zero at time $\mathrm{t}=\mathrm{t}_{1}$. For manufacturing cycle, $\mathrm{I}_{\mathrm{m}}(\mathrm{t})$ denotes the inventory level at time $t$. The manufacturing process starts at time $t=0$ and the inventory level of perfect items increases at a rate $p_{2}-d-\frac{E\left(n_{2}\right)}{t_{m}}(>0)$ until time $\mathrm{t}=\mathrm{t}_{\mathrm{m}}$, where the production process stopped. Expected number of imperfect items produced in manufacturing process of which $\beta$ portion ( $0<\beta<1)$ i, e $\beta E\left(n_{2}\right)$ amount are rework at rework position at $\mathrm{t}=\mathrm{t}_{\mathrm{m}}$, at the end of production process. Then the inventory level decline continuously at a rate $d$, where it becomes zero at time $\mathrm{t}=\mathrm{t}_{2}$ (the end of the production cycle ). Also for returned cycle, $\mathrm{I}_{\mathrm{r}}(\mathrm{t})$ denotes the inventory level at time $t$. As the remanufacturing system starts at a time $t=0$, the inventory level of returned items decreases at a rate $\left(-p_{1}+r\right)$ until time $\mathrm{t}=\mathrm{t}_{\mathrm{p}}$ by which the remanufacturing process ceased and the inventory level of returned item become zero. The inventory level starts to up with a rate $\mathrm{r}$ until time $\mathrm{t}=\mathrm{t}_{1}$. When the production process starts, the imperfect items are produced at a rate $\frac{E\left(n_{2}\right)}{t_{m}}$ and piles up them up to $\mathrm{t}=\mathrm{t}_{\mathrm{m}}$. Among the inventory of imperfect items, $\beta \mathrm{E}\left(\mathrm{n}_{2}\right)$ portion are make as good as new by some rework and stock them with the perfect items. Rest portion of the imperfect items are stock with the returned items for use as raw-materials in re-manufacturing process. So the inventory level of returned item go-up at a rate $\left(\mathrm{r}+\mathrm{E}\left(\mathrm{n}_{2}\right) / \mathrm{t}_{\mathrm{m}}\right)$ up to time $\mathrm{t}=\mathrm{t}_{\mathrm{m}}$ and same at a rate $\mathrm{r}$ from time $\mathrm{t}=\mathrm{t}_{\mathrm{m}}$ to $\mathrm{t}=\mathrm{t}_{2}$.

The behavior of such a unified system is depicted in Figure-1. 


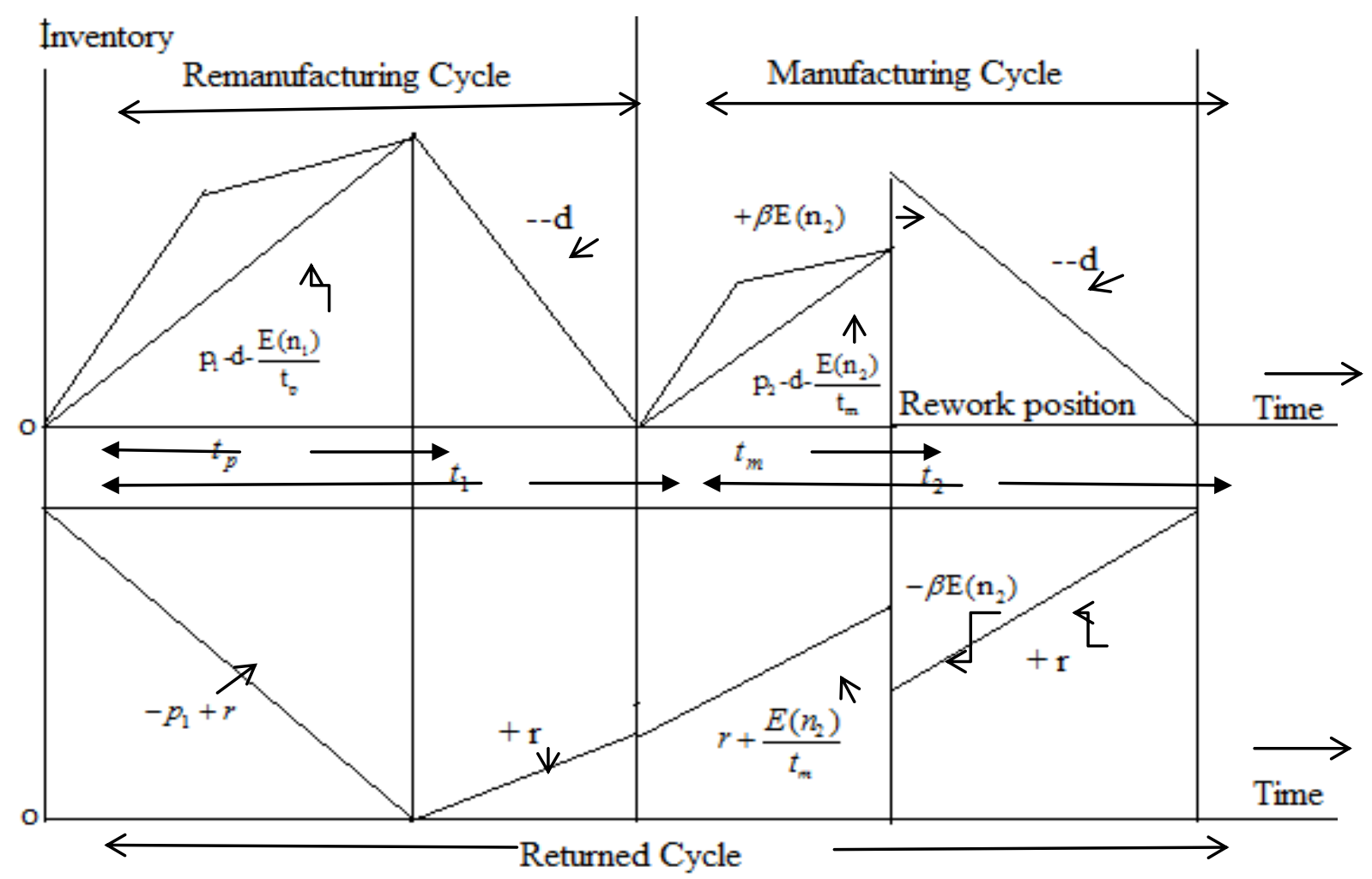

Figure : 1 ( Inventory of Manufacturing, Remanufacturing and Returned items in a single management)

\subsection{The inventory level are governed by the following differential equations}

\subsubsection{Remanufacturing Process}

The differential equation of the system is

$$
\frac{d I_{r m}(t)}{d t}=\left\{\begin{array}{cc}
p_{1}-d-\frac{E\left(n_{1}\right)}{t_{p}}: & 0 \leq t \leq t_{p} \\
-d & : t_{p} \leq t \leq t_{1}
\end{array}\right.
$$

with $I_{\mathrm{rm}}(0)=0$ and with $\mathrm{I}_{\mathrm{rm}}\left(\mathrm{t}_{1}\right)=0$. Where $\mathrm{E}\left(\mathrm{n}_{1}\right)$ is the expected number of imperfect items produced during the remanufacturing up time.

\subsubsection{Manufacturing Process}

The differential equation of the system is

$$
\frac{d I_{m}(t)}{d t}= \begin{cases}p_{2}-d-\frac{E\left(n_{2}\right)}{t_{m}} & : 0 \leq t \leq t_{m} \\ -d & : t_{m} \leq t \leq t_{2}\end{cases}
$$

with $I_{m}(0)=0$ and with $I_{m}\left(t_{2}\right)=0$. Where $E\left(n_{2}\right)$ is the expected number of imperfect items produced during the manufacturing up time.

In manufacturing/ Production process, the imperfect quality product is produce with the rate $\mathrm{E}\left(\mathrm{n}_{2}\right) / \mathrm{t}_{\mathrm{m}}$ during the time interval $\left(0, t_{m}\right)$, which are stocked in the returned cycle for future remanufacturing and rework. At the time point $\mathrm{t}_{\mathrm{m}}$ (rework position), $\beta E\left(n_{2}\right) \quad(\beta, 0<\beta<1$, a real constant) amount of imperfect items are rework and other portion of this i.e. $(1-\beta) E\left(n_{2}\right)$ are kept for remanufacturing. The reworked items are as good as new and are depleted by the demand $\mathrm{d}$.

\subsubsection{Returned Process:}

The differential equation of the system is

$$
\frac{d I_{r}(t)}{d t}=\left\{\begin{array}{cl}
-p+r & : 0 \leq \mathrm{t} \leq \mathrm{t}_{\mathrm{p}} \\
r & : \mathrm{t}_{\mathrm{p}} \leq \mathrm{t} \leq \mathrm{t}_{1} \\
r+\frac{E\left(n_{2}\right)}{t_{m}} & : 0 \leq \mathrm{t} \leq \mathrm{t}_{\mathrm{m}} \\
r & : t_{m} \leq t \leq t_{2}
\end{array}\right.
$$

with $\mathrm{I}_{\mathrm{r}}\left(\mathrm{t}_{\mathrm{p}}\right)=0$ and $\mathrm{I}_{\mathrm{r}}(0)=\mathrm{I}_{\mathrm{r}}(\mathrm{T})$.

Inventory holding cost for good quality items in remanufacturing system is

$Z_{1}=\frac{h_{r m}}{2 d}\left[\left(p_{1} t_{p}-E\left(n_{1}\right)\right)\left(\left(p_{1}-d\right) t_{p}-E\left(n_{1}\right)\right)\right]$

Inventory holding cost for good quality items in manufacturing system is

$$
\begin{aligned}
& Z_{2}= \frac{h_{m}}{2}\left[\left(p_{2}-d\right) t_{m}^{2}-E\left(n_{2}\right) t_{m}+\right. \\
&\left.\quad\left(\left(p_{2}-d\right) t_{m}-(1-\beta) E\left(n_{2}\right)\right)^{2} / d\right]
\end{aligned}
$$

Inventory holding cost for returned item is

$$
\begin{aligned}
Z_{3} & =\frac{h_{r}}{2}\left[\left(p_{1}-r\right) t_{p}^{2}+r\left(t_{1}+t_{2}-t_{p}\right)^{2}+E\left(n_{2}\right) t_{m}\right. \\
& \left.+2(1-\beta) E\left(n_{2}\right)\left(t_{2}-t_{m}\right)\right]
\end{aligned}
$$

The relation between the remanufacturing up time, remanufacturing cycle time, manufacturing up time, manufacturing cycle and total length of the production cycle for both remanufacturing and manufacturing (consider as single management) are as follows.

$t_{1}=\left(p_{1} t_{p}-E\left(n_{1}\right)\right) / d, t_{2}=\left(p_{2} t_{m}-(1-\beta) E\left(n_{2}\right)\right) / d$

And $\mathrm{T}=\mathrm{t}_{1}+\mathrm{t}_{2}$

$$
=\left(p_{1} t_{p}+p_{2} t_{m}-E\left(n_{1}\right)-(1-\beta) E\left(n_{2}\right)\right) / d
$$

Again inventory of the returned items at the end of manufacturing cycle is same as the inventory of the returned items at the beginning of the remanufacturing process, which 
gives the relation between the remanufacturing up time and manufacturing up time. Therefore it follows that

$r p_{2} t_{m}+(d-r)(1-\beta) E\left(n_{2}\right)=p_{1}(d-r) t_{p}+r E\left(n_{1}\right)$

Total cost of production process consists, setup cost , manufacturing cost, remanufacturing cost, screening cost , returned item collected cost, rework cost, disposal cost of imperfect items from the remanufacturing process, and environmental protection cost.

The total cost for the production process during the production cycle $(0, \mathrm{~T})$ is

$$
\begin{aligned}
& T C\left(t_{p}, t_{m}\right)=k+\left(\frac{d\left(c_{r m}+c_{s}\right)+r\left(c_{s}+c_{r}\right)}{d}\right) p_{1} t_{p}+\left(\frac{d\left(c_{m}+c_{s}\right)+r\left(c_{s}+c_{r}\right)}{d}\right) \\
& p_{2} t_{m}+E\left(n_{1}\right)\left(\frac{d\left(c_{d m}+c_{e}\right)-r\left(c_{s}+c_{r}\right)}{d}\right)+\left(\frac{d \beta c_{r r}-(1-\beta) r\left(c_{s}+c_{r}\right)}{d}\right) E\left(n_{2}\right) \\
& +\frac{h_{r m}}{2 d}\left(\left(p_{1} t_{p}-E\left(n_{1}\right)\right)\left(\left(p_{1}-d\right) t_{p}-E\left(n_{1}\right)\right)\right)+\frac{h_{m}}{2}\left(\left(p_{2}-d\right) t_{m}^{2}-E\left(n_{2}\right) t_{m}+\right. \\
& \left.\left(\left(p_{2}-d\right) t_{m}-(1-\beta) E\left(n_{2}\right)\right)^{2} / d\right)+\frac{h_{r}}{2}\left(\left(p_{1}-r\right) t_{p}^{2}+E\left(n_{2}\right) t_{m}+r\left(t_{1}+t_{2}-t_{p}\right)^{2}\right. \\
& \left.+2(1-\beta) E\left(n_{2}\right)\left(t_{2}-t_{m}\right)\right)
\end{aligned}
$$

Using the relation (7) and (8), one can reduce equation (9) and it follows that ,total cost per unit time is

$$
\begin{aligned}
& A T C\left(t_{p}\right)=\left[k+\left(\frac{d\left(c_{r m}+c_{s}\right)+r\left(c_{s}+c_{r}\right)}{d}\right) p_{1} t_{p}\right. \\
& +\left(\frac{d\left(c_{m}+c_{s}\right)+r\left(c_{s}+c_{r}\right)}{d}\right) p_{2} t_{m}+ \\
& \left(\frac{d\left(c_{d m}+c_{e}\right)-r\left(c_{s}+c_{r}\right)}{d}\right) E\left(n_{1}\right) \\
& +\left(\frac{d \beta c_{r r}-(1-\beta) r\left(c_{s}+c_{r}\right)}{d}\right) E\left(n_{2}\right) \\
& +\frac{h_{r m}}{2 d}\left(\left(p_{1} t_{p}-E\left(n_{1}\right)\right)\left(\left(p_{1}-d\right) t_{p}-E\left(n_{1}\right)\right)\right) \\
& +\frac{h_{m}}{2}\left(\left(p_{2}-d\right) t_{m}^{2}-E\left(n_{2}\right) t_{m}+\left(\left(p_{2}-d\right) t_{m}-\right.\right. \\
& \left.\left.(1-\beta) E\left(n_{2}\right)\right)^{2} / d\right)+\frac{h_{r}}{2}\left(\left(p_{1}-r\right) t_{p}^{2}+E\left(n_{2}\right) t_{m}\right. \\
& \left.\left.+r\left(t_{1}+t_{2}-t_{p}\right)^{2}+2(1-\beta) E\left(n_{2}\right)\left(t_{2}-t_{m}\right)\right)\right] / T
\end{aligned}
$$

\subsubsection{Total Cost as a function of return lot.}

In remanufacturing process, consider $\mathrm{V}$ be the random variable, denoting the time for shifting from in-control state to the out of control state and $\mathrm{f}(\mathrm{v})$ be the corresponding density function. Similarly in manufacturing process, $U$ be the random variable, denoting the time for shifting from incontrol state to the out of control state and $g(u)$ be the corresponding density function. Consider $\mathrm{V}$ and $\mathrm{U}$ are both follows the uniform distribution. So,

$E\left(n_{1}\right)=\frac{\delta p_{1} t_{p}}{2}$ and $E\left(n_{2}\right)=\frac{\mu p_{2} t_{m}}{2}$

Let $\mathrm{Q}$ be the total returned items lot, then

$T=\frac{Q}{r}$ and $\quad p_{1} t_{p}=Q+(1-\beta) \frac{\mu p_{2}}{2} t_{m}$, gives

$t_{p}=X Q \quad, t_{m}=Y Q$

Where, $X=\frac{2(2 r+(d-r)(1-\beta) \mu)}{p_{1} r(4-(1-\beta) \mu \delta)}$ and

$$
Y=\frac{2(2(d-r)+r \delta)}{p_{2} r(4-(1-\beta) \mu \delta)}
$$

$$
t_{1}=\frac{p_{1} X(2-\delta)}{2 d} Q=U Q
$$

And

$$
t_{2}=\frac{p_{2} Y(2-(1-\beta) \mu)}{2 d} Q=V Q
$$

$$
E\left(n_{1}\right)=\frac{\delta p_{1} X}{2} Q=\mathrm{AQ}
$$

and $E\left(n_{2}\right)=\frac{\mu p_{2} Y}{2} Q=B Q$

$U=\frac{(2-\delta)(2 r+(d-r)(1-\beta) \mu)}{r d(4-(1-\beta) \mu \delta)}$

$V=\frac{(2-(1-\beta) \mu)(2(d-r)+\delta r)}{r d(4-(1-\beta) \mu \delta)}$

$A=\frac{\delta(2 r+(d-r)(1-\beta) \mu)}{r(4-(1-\beta) \mu \delta)}$

$B=\frac{\mu(2(d-r)+\delta r)}{r(4-(1-\beta) \mu \delta)}$

Using equations from(11) to(17), (10) becomes a function of Q.

$$
\begin{array}{r}
A T C(Q)=r\left[\left(\frac{d\left(c_{r m}+c_{s}\right)+r\left(c_{s}+c_{r}\right)}{d}\right) p_{1}\right. \\
X Q+k+\left(\frac{d\left(c_{m}+c_{s}\right)+r\left(c_{s}+c_{r}\right)}{d}\right) p_{2} Y Q \\
+\left(\frac{d\left(c_{d m}+c_{e}\right)-r\left(c_{s}+c_{r}\right)}{d}\right) A Q \\
+\left(\frac{d \beta c_{r r}-(1-\beta) r\left(c_{s}+c_{r}\right)}{d}\right) B Q \\
+\frac{h_{r m}}{2 d}\left(( p _ { 1 } X Q - A Q ) \left(\left(p_{1}-d\right) X Q-\right.\right. \\
A Q))+\frac{h_{m}}{2 d}\left(d\left(p_{2}-d\right) Y^{2} Q^{2}-d B Y Q^{2}\right. \\
\left.+\left(\left(p_{2}-d\right) Y Q-(1-\beta) B Q\right)^{2}\right)+ \\
\frac{h_{r}}{2 r}\left(r\left(p_{1}-r\right) X^{2} Q^{2}+r B Y Q^{2}+(Q-r X Q)^{2}\right. \\
+2(1-\beta) r B Q(V Q-Y Q))] / Q
\end{array}
$$

\subsection{Solution Procedure}

To obtain the optimal solution of proposed reverse logistic model ( manufacturing, remanufacturing and return item from the market), we minimize the objective function ATC(Q) with respect to Q. So, taking $\frac{d A T C(Q)}{d Q}=0$, solving we get $\mathrm{Q}^{*}$ and for which $\frac{d^{2} \operatorname{ATC}(Q)}{d^{2} Q}>0$ for $Q^{*}>0$.

Theorem 1:. The global optimum (minimum) of ATC (Q) exists, when the relation $\frac{2 r}{\sqrt{k}}>N^{\frac{3}{2}}$ is hold. Where

$$
\begin{aligned}
& N=\frac{h_{r m}}{2 d}\left[p_{1} X-A\right)\left(\left(p_{1}-d\right) X-A\right]+\frac{h_{m}}{2 d}\left[d\left(p_{2}-d\right)\right. \\
& \left.Y^{2}-B d Y+\left(\left(p_{2}-d\right) Y-(1-\beta) B\right)^{2}\right]+\frac{h_{r}}{2 r}\left[r\left(p_{1}-r\right)\right. \\
& \left.X^{2}+r B Y+(1-r X)^{2}+2(1-\beta) r B(V-Y)\right]
\end{aligned}
$$

and $\mathrm{X}, \mathrm{Y}, \mathrm{A}, \mathrm{B}, \mathrm{U}$ and $\mathrm{V}$ are given in equation (13), (14) and (18). 
Proof: Our objective function $\mathrm{ATC}(\mathrm{Q})$ can written in the form $f(Q)=\frac{r\left[k+M Q+N Q^{2}\right]}{Q}$. The necessary condition for optimum solution is $\frac{d f(Q)}{d Q}=0$, which gives $Q= \pm \sqrt{\frac{k}{N}}$ and corresponding sufficient condition $\frac{d^{2} f(Q)}{d Q^{2}}>0$ for $Q>0$. From which it follows the result equation (20).

\subsection{Numerical Examples}

The parametric values in the model are as $\mathrm{k}=2000, \mathrm{p}_{1}=200$ $, \mathrm{p}_{2}=175, \mathrm{~d}=150, \mathrm{r}=40, \beta=0.5, \delta=0.25, \mu=0.25, \mathrm{c}_{\mathrm{rm}}$ $=35, \mathrm{c}_{\mathrm{m}}=50, \mathrm{c}_{\mathrm{r}}=5, \mathrm{c}_{\mathrm{s}}=5, \mathrm{c}_{\mathrm{dm}}=2, \mathrm{c}_{\mathrm{e}}=2, \mathrm{c}_{\mathrm{rr}}=5, \mathrm{~h}_{\mathrm{rm}}=$ $10, \mathrm{~h}_{\mathrm{m}}=10, \mathrm{~h}_{\mathrm{r}}=8$.

We analyses the effect of return rate of items on the optimum total cost per unit returned item.

Table : 1. The Optimal results for the reverse logistic model (Manufacturing - Remanufacturing - Return) under the above parametric values are as follows:

\begin{tabular}{|c|c|c|c|}
\hline $\mathrm{Q}^{*}$ & $\mathrm{t}_{\mathrm{p}}{ }^{*}$ & $\mathrm{t}_{1}{ }^{*}$ & $\mathrm{t}_{\mathrm{m}}{ }^{*}$ \\
\hline 130.15 & 0.768602 & 0.896703 & 2.15501 \\
\hline \multicolumn{2}{|c|}{$\mathrm{t}_{2}{ }^{*}$} & $\mathrm{~T}^{{ }^{*}}$ & $\mathrm{ATC}\left(\mathrm{Q}^{*}\right)$ \\
\hline 2.35705 & 3.25375 & 9953.76 \\
\hline
\end{tabular}

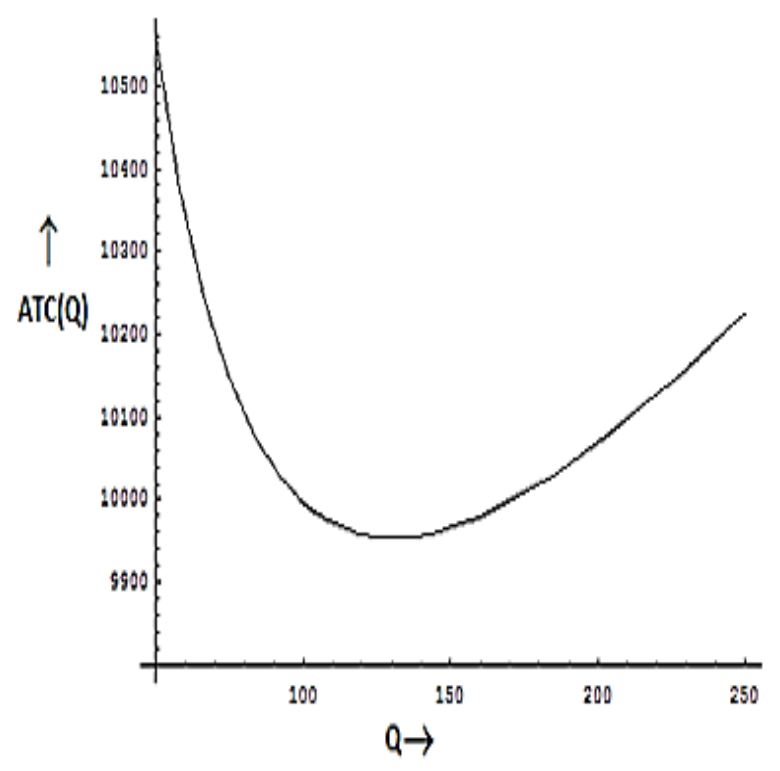

Figure:2 Convexity of $\mathrm{ATC}(\mathrm{Q})$ with respect to $Q$.

\subsection{Sensitivity Analysis}

Table : 2. The Optimal results for the reverse logistic model (Manufacturing—Remanufacturing — Return) with the above parametric values under different return rates are as follows:

\begin{tabular}{|c|c|c|c|c|c|c|c|}
\hline $\begin{array}{c}\text { Return rate } \\
(\mathrm{r}=40)\end{array}$ & $\mathrm{Q}^{*}$ & $\mathrm{t}_{\mathrm{p}}{ }^{*}$ & $\mathrm{t}_{1}{ }^{*}$ & $\mathrm{t}_{\mathrm{m}}{ }^{*}$ & $\mathrm{t}_{2}{ }^{*}$ & $\mathrm{~T}^{*}$ & $\mathrm{ATC}\left(\mathrm{Q}^{*}\right)$ \\
\hline$-20 \%$ & 108.91 & 0.675328 & 0.787882 & 2.39136 & 2.61556 & 3.40344 & 9903.78 \\
$-10 \%$ & 119.66 & 0.722393 & 0.842792 & 2.26858 & 2.48126 & 3.32406 & 9929.80 \\
$-5 \%$ & 124.94 & 0.745601 & 0.869868 & 2.21077 & 2.41803 & 3.28789 & 9942.03 \\
0 & 130.15 & 0.768602 & 0.896703 & 2.15501 & 2.35705 & 3.25375 & 9953.76 \\
$+5 \%$ & 135.31 & 0.791441 & 0.923398 & 2.10123 & 2.29822 & 3.22157 & 9965.07 \\
$10 \%$ & 140.42 & 0.814175 & 0.949870 & 2.04937 & 2.24149 & 3.19136 & 9975.79 \\
$20 \%$ & 150.51 & 0.859211 & 1.00241 & 1.95037 & 2.13321 & 3.13563 & 9995.99 \\
\hline
\end{tabular}

Table : 3. The Optimal results for the reverse logistic model (Manufacturing—Remanufacturing — Return) with the above parametric values under different remanufacturing rates are as follows:

\begin{tabular}{|c|c|c|c|c|c|c|c|}
\hline $\begin{array}{c}\text { Remanufacturing } \\
\text { rate }\left(\mathrm{p}_{1}=200\right)\end{array}$ & $\mathrm{Q}^{*}$ & $\mathrm{t}_{\mathrm{p}}{ }^{*}$ & $\mathrm{t}_{1}{ }^{*}$ & $\mathrm{t}_{\mathrm{m}}{ }^{*}$ & $\mathrm{t}_{2}{ }^{*}$ & $\mathrm{~T}^{*}$ & $\mathrm{ATC}\left(\mathrm{Q}^{*}\right)$ \\
\hline$-10 \%$ & 133.31 & 0.874738 & 0.918474 & 2.20734 & 2.41428 & 3.33275 & 9924.58 \\
$-5 \%$ & 131.62 & 0.818193 & 0.906831 & 2.17935 & 2.38367 & 3.29050 & 9940.53 \\
0 & 130.15 & 0.768602 & 0.896703 & 2.15501 & 2.35705 & 3.25375 & 9953.76 \\
$5 \%$ & 128.86 & 0.724747 & 0.887815 & 2.13365 & 2.33369 & 3.22150 & 9966.06 \\
$10 \%$ & 127.72 & 0.685684 & 0.879961 & 2.11478 & 2.31304 & 3.19300 & 9977.14 \\
\hline
\end{tabular}

Table : 4. The Optimal results for the reverse logistic model (Manufacturing - Remanufacturing -Return) with the above parametric values under different manufacturing rates are as follows:

\begin{tabular}{|c|c|c|c|c|c|c|c|}
\hline $\begin{array}{c}\text { Manufacturing } \\
\text { rate }\left(\mathrm{p}_{2}=175\right)\end{array}$ & $\mathrm{Q}^{*}$ & $\mathrm{t}_{\mathrm{p}}{ }^{*}$ & $\mathrm{t}_{1}{ }^{*}$ & $\mathrm{t}_{\mathrm{m}}{ }^{*}$ & $\mathrm{t}_{2}{ }^{*}$ & $\mathrm{~T}^{*}$ & $\mathrm{ATC}\left(\mathrm{Q}^{*}\right)$ \\
\hline$-10 \%$ & 147.91 & 0.873480 & 1.019060 & 2.72120 & 2.67869 & 3.69775 & 9806.14 \\
$-5 \%$ & 137.72 & 0.813310 & 0.948860 & 2.40038 & 2.44941 & 3.44300 & 9886.18 \\
0 & 130.15 & 0.768602 & 0.896703 & 2.15501 & 2.35705 & 3.25375 & 9953.76 \\
$5 \%$ & 124.28 & 0.733940 & $0 . .85626$ & 1.95983 & 2.25074 & 3.10700 & 10011.90 \\
$10 \%$ & 119.57 & 0.706122 & 0.823810 & 1.79985 & 2.16544 & 2.98925 & 10062.50 \\
\hline
\end{tabular}


Table : 5. The Optimal results for the reverse logistic model (Manufacturing—Remanufacturing — Return) with the above parametric values under different Setup Cost are as follows:

\begin{tabular}{|c|c|c|c|c|c|c|c|}
\hline $\begin{array}{c}\text { Setup Cost } \\
(\mathrm{K}=2000)\end{array}$ & $\mathrm{Q}^{*}$ & $\mathrm{t}_{\mathrm{p}}{ }^{*}$ & $\mathrm{t}_{1}{ }^{*}$ & $\mathrm{t}_{\mathrm{m}}{ }^{*}$ & $\mathrm{t}_{2}{ }^{*}$ & $\mathrm{~T}^{*}$ & ATC $\left(\mathrm{Q}^{*}\right)$ \\
\hline$-10 \%$ & 123.47 & 0.729154 & 0.850679 & 2.04441 & 2.23607 & 3.08675 & 9890.68 \\
$-5 \%$ & 126.85 & 0.749114 & 0.873967 & 2.10037 & 2.29728 & 3.17125 & 9922.64 \\
0 & 130.15 & 0.768602 & 0.896703 & 2.15501 & 2.35705 & 3.25375 & 9953.76 \\
$5 \%$ & 133.36 & 0.787559 & 0.918819 & 2.20817 & 2.41578 & 3.33400 & 9984.12 \\
$10 \%$ & 136.50 & 0.806102 & 0.940453 & 2.26016 & 2.47255 & 3.41250 & 10013.80 \\
\hline
\end{tabular}

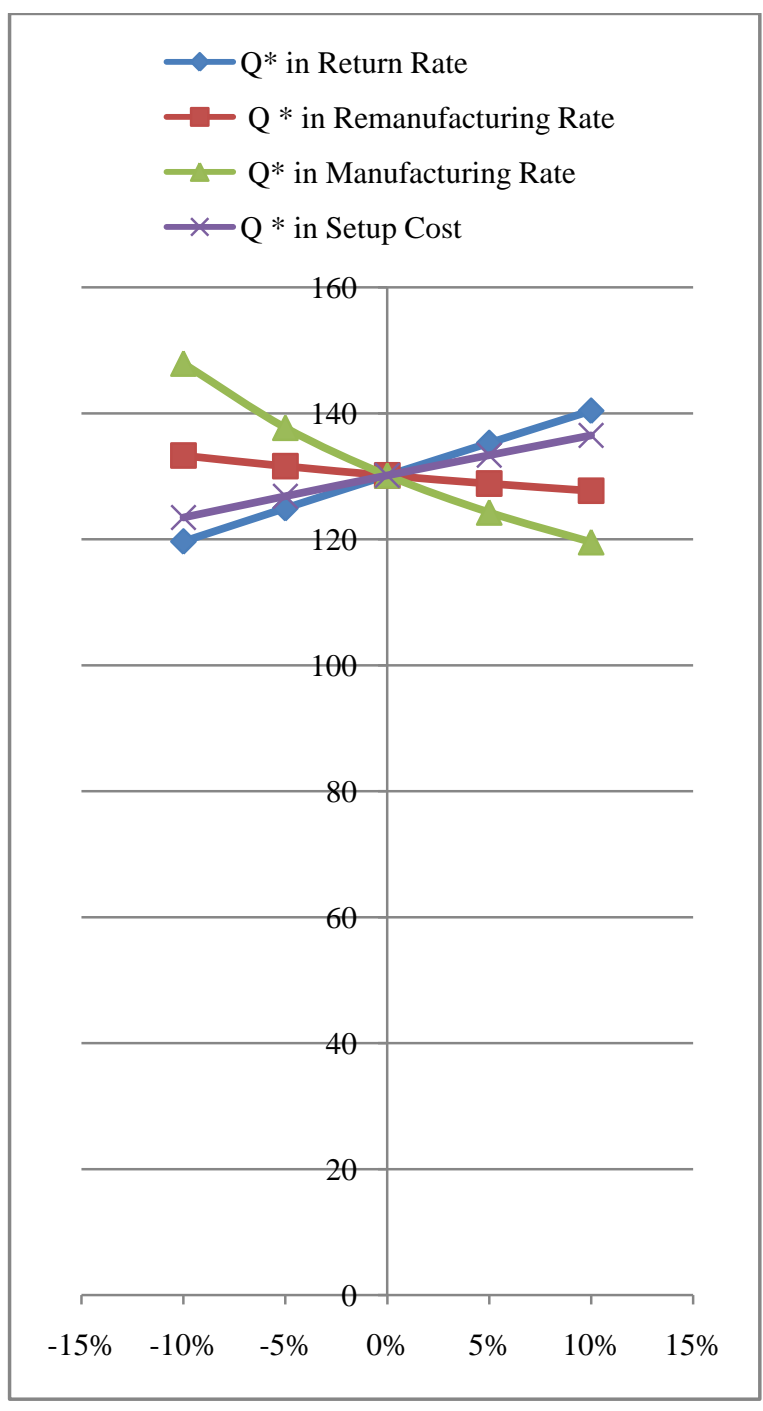

Figure 3 Optimum Return lot of product for different change in parameter

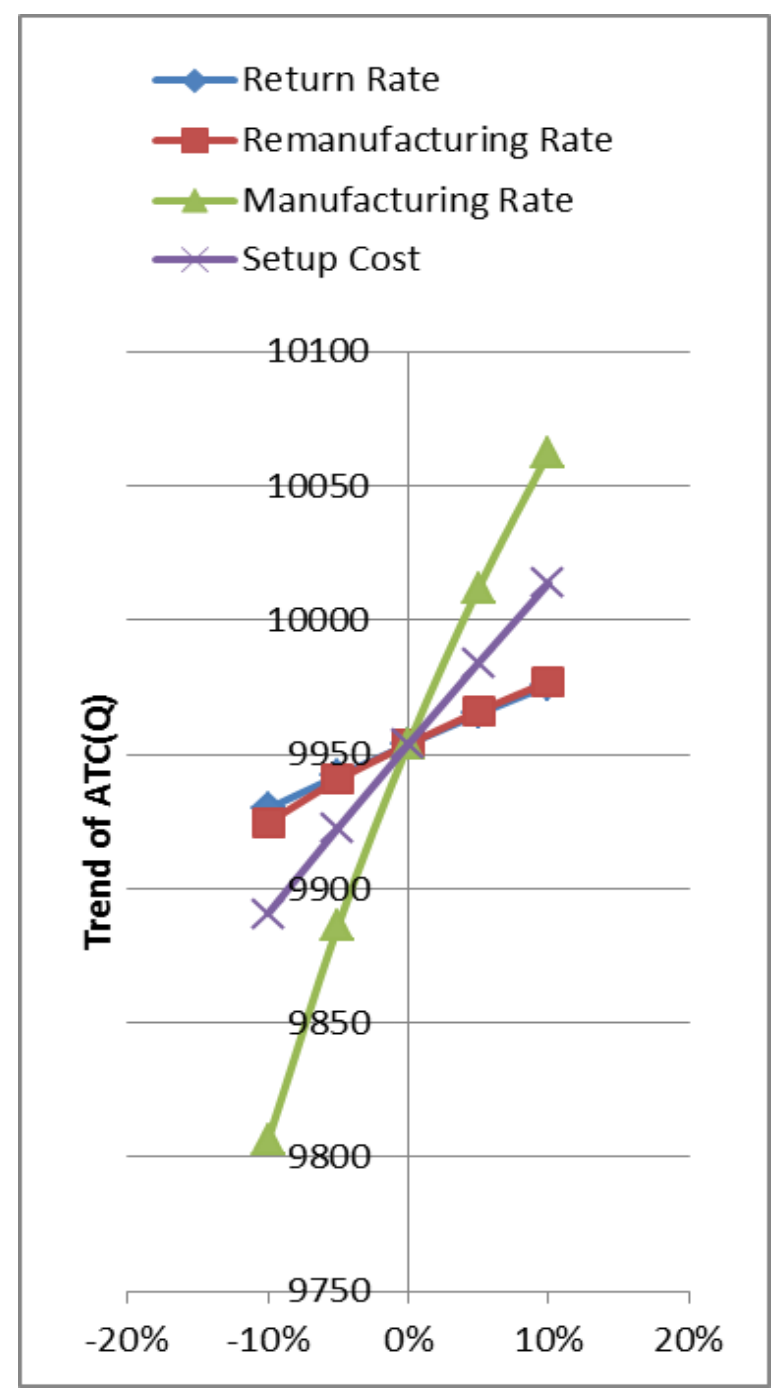

Figure : 4 Optimum total cost for different change in parameter

From table : 2 and Figure : 3 , we observe that increasing of return rate causes increasing of return lot which is obvious consequently greater return lot effect on remanufacturing time, remanufacturing cycle, manufacturing time, manufacturing cycle and total cost per unit time. The remanufacturing time, remanufacturing cycle increases and manufacturing time, manufacturing cycle decreases with the increasing return rate and return lot.. In the same time total time for single management is decreases. $Q^{*}$ is slightly sensitive on return rate.

From table : 3 and Figure : 3 , we observe that increasing of remanufacturing rate causes decreasing of return lot. The fewer return lot, effect on remanufacturing time, 
remanufacturing cycle, manufacturing time, manufacturing cycle and total cost per unit time. The remanufacturing time, remanufacturing cycle, manufacturing time, and manufacturing cycle decreases with the increasing remanufacturing rate and fewer return lot.. In the same time total time for single management is decreases. $Q^{*}$ is moderately sensitive on remanufacturing rate.

From table :4 and figure :3, it follows that increasing of manufacturing rate implies fewer return lot, for which, remanufacturing time, manufacturing time, remanufacturing cycle and manufacturing cycle all decreases and total time for single management is decreases. $Q^{*}$ is slightly sensitive on manufacturing rate.

From table :5 and figure :3, it is observe that increase of setup cost increases return lot and consequently total time for single management system is more. Here $Q^{*}$ is fairly sensitive (insensitive) on setup cost.

Again, optimum total cost per unit return item $A T C\left(Q^{*}\right)$ is increases with increasing change of all parameter. It is highly sensitive with change in manufacturing rate., slightly sensitive with setup cost and fairly sensitive with return rate and remanufacturing rate.

\section{CONCLUSION}

In this paper, a reverse logistics integrated economic production inventory model of imperfect item for manufacturing of new items and remanufacturing of returned item along with remanufacturing of defectives items in the imperfect manufacturing is investigated. Here, one can observe that the increment of rate of manufacturing and rate of remanufacturing implies the decrement of acceptable returned quantity causes very little decrease of total cost per unit time. But however an unexpected increment of total cost per unit time is happened due to the reduction of total cycle length for single management system. The increment of returned rate of items, i.e., increase of return lot follows the total time for producing new item is decreases consequently production cost of new item decreases, which reduce the total cost per unit time. So, raw materials for the manufacturing system for new items can be brought with less cost in the form of returned items for remanufacturing. In this article both the manufacturing and remanufacturing process are imperfect, so produces imperfect items. Some portion of imperfect product in the manufacturing process are consider for the input resources of remanufacturing for total uses of raw material with less cost. For environment consciousness, use of return item as input and dispose the imperfect product in remanufacturing process with some minimum cost effect the protection of our live environment and control the total pollution. This paper suggest that the manufacturer should appoint efficient technician to reduce the imperfect item, proper functioning of both the process and efficient collection of returned item to use as input. This paper focuses the reverse logistic supply chain with the development of imperfect production process which determines the optimum returned lot and optimum cost per unit time.

\section{ACKNOWLEDGEMENTS}

Prasanta Kumar Ghosh thanks the Minor Research Project, UGC (PSW-141, 13/14 UGC, Govt. of India) for financial support to do this research work.

\section{REFERENCES}

[1] Almari, A. A. (2011). Theory and methodology on the global optimal solution to a general reverse logistic inventory model for deteriorating items and time varying rates, Computer and Industrial Engineering, 60(2), 236247.

[2] Ben-Daya,M., Hariga,M.(2000). Economic lot scheduling problem with imperfect production processes: Journal of the Operational Research Society, 51, 875881.

[3] Chung, K.J.,Hou, K.L.(2003).An optimal production run time with imperfect production processes and allowable shortages: Computers and Operations Research, 20, 483490.

[4] Dobos, I. and Richter, K. (2003). A production/recycling model with stationary demand and return rates, Central European Journal of Operational Research, 11 (1), 35-46.

[5] Dobos, I. and Richter, K. (2004). An extended production /recycling model with stationary demand and return rates, International Journal of Production Economics, 90(3), 311-323.

[6] Dobos, I. and Richter, K. (2006).A production /recycling model with quality considerations. International Journal of Production Economics, 104(2), 571-579.

[7] Ghosh, Prasanta Kumar and Dey, Jayanta Kumar (2016). Optimal Imperfect Production Inventory Model with Machine Breakdown and Stochastic Repair Time, World Journal of Research and Review, 3(1), 59-65.

[8] Goyal, S.K., Cardenas-Barron, L.E.(2002).Note on: Economic production quantity model for items with imperfect quality-a practical approach: International Journal of Production Economics,77,85-87.

[9] Goyal, S.K., Hung, C.K., Chen, H.K.(2003).A simple integrated production policy of an imperfect item for vender and buyer Production Planning and Control, 14, 596-602.

[10] Hayek,P.A., Salameh. M.K.,[2001]:Production lot sizing with the reworking of imperfect quality items produced. Production Planning and Control12,584-590.

[11] Hazari,S.,,Maity, K., Dey, J. K. and Kar, S. (2014a).Optimal dynamic production and price for reliability-dependent imperfect production with inventory-level-dependent demand in uncertain environment, Journal of Uncertainty Analysis and Applications, 2(9),2014.

[12] Hazari, S., Maity, K., Dey, J. K. and Kar, S. (2014b). An Interactive Method for Two-plants Production Inventory Control with Two-Warehouse Facility under Imprecise Environment, International Journal of Computer Applications, 96(21), 1-13, 2014.

[13] Hazari, S., Maity, K., Dey, J. K. and Kar, S. (2015).Advertisement policy and reliability dependent imperfect production inventory control problem in bifuzzy environment. International Journal of Operational Research, 22(3), 342-365.

[14] Inderfurth, K., Lindner, G. and Rachaniotis, N. P. (2005).Lot sizing in a production system with rework and product deterioration. International Journal of Production Research, 43(7), 1355-1374. 
[15] Jabar, M.Y. and Rosen, M.A (2008), The economic order quantity repair and waste disposal model with entropy cost, European Journal of Operational Research, 108 (1), 109-120.

[16] Jaber, M.Y. and El Saadany, Ahmed M.A (2010).An economic production and remanufacturing model with learning effects, International Journal of Production Economics, 104(2), 571-579.

[17] Konstantaras, I. and and Papachristos, S. (2006).Lot sizing for a single-product recovery system with backordering, International Journal of Production Research, 44(10), 2031-2045.

[18] Manna, A.K., Dey, J.K., Mondal, S.K.(2014).Three-layer supply chain in an imperfect production inventory model with two storage facilities under fuzzy rough environment. Journal of Uncertainty Analysis and Applications: 2:17.

[19] Manna, A.K., Dey, J.K., B. Das and Mondal, S.K.(2016).An EPQ model with promotional demand in random planning horizon: population varying genetic algorithm approach. Journal of Intelligent Manufacturing,1-17.

[20] Nahmias, S and Rivera, H. (1979).A deterministic model for a repairable item inventory system with a finite repair rate, International Journal of Production Research, 17(3), 215-221.

[21] Nenes, G., Panagiotidou, S. and Dekker, R. (2010). Inventory control policies for inspections and remanufacturing of returns: A case study, International
Journal of Production Economics, 125, 300-312.

[22] Richter, K. (1996a). The EOQ repair and waste disposal model with variable setup numbers. European Journal of Operational Research, 95 (2), 313-324.

[23] Richter, K. (1996b). The extended EOQ repair and waste disposal model, International. Journal of Production Economics, 45 (1-3), 443-447.

[24] Richter, K. (1997). Pure and mixed strategies for the EOQ repair and waste disposal problem, OR Spectrum, $19(2), 123-129$.

[25] Rosenblatt.M.J., Lee H.L.,[1986]: Economic production cycle with imperfect production process.IIE Transactions 17,48-54

[26] Sana.S.,GoyelS.K.,Chaudhuri K.S.,[2007a]:An imperfect production process in a volume flexible inventory model. International Journal of Production Economics 105.548559.

[27] Schrady, D.A. (1967).A deterministic inventory model for repairable items, Naval Research Logistics Quarterly, 14(3), 391-398

[28] Teunter, R.H. (2001). Economic ordering quantities for recoverable item inventory system, Naval Research Logistics Quarterly, 48(6), 484-495.

[29] Teunter, R.H. (2004).Lot-sizing for inventory systems with product recovery, Computer and Industrial Engineering, 46(3), 431-441. 